\title{
Symposium 3
}

\section{Vivisection, morals, medicine: commentary from a vivisecting professor of pharmacology}

\author{
Sir William Paton University of Oxford
}

It would be best to start by summarising what (for this comment) I take to be the essential points of Dr Frey's interesting, and I believe novel, argument. 1) A major justification of animal experiment, commonly accepted, is the benefit that results. 2) This justification is rejected by some, initially on the grounds that the benefit does not justify the pain inflicted; but when it is noted that experiments may be painless, or that steps are taken to minimise the pain, the fundamental ground of rejection is revealed by a shift to the statement that the use of animals for these purposes is absolutely wrong. 3) Those who argue this way will accept the loss of the benefits. 4) But is it necessary to forego these benefits? Why not, in order to retain them, be willing to use man for these experiments? 5) If it is said against this that man is more valuable than animals, in what way is this so? 6) Dr Frey does not believe in 'souls', nor does he accept the 'dominion' of man, and he can only identify 'capacity for enrichment' as a suitable defining characteristic of humanity. 7) $\mathrm{He}$ finds that this criterion does not separate man from animals; for instance, he concludes that some animals may possess more of this capacity than some humans (for example, the very, very severely mentally enfeebled or spina bifida children). 8) He therefore accepts (with great reluctance) that human experiment should be permissible, with due precaution, in order to obtain the benefits concerned. 9) While acknowledging that the side-effects of such experiment (society's outrage, damage to doctor-patient relations) might prevent particular experiments, their occurrence would be 'utterly contingent', and would not negate the general principle of permissibility.

It is not always clear whether Dr Frey himself holds the views expressed, or is doing no more than presenting them for discussion. In the latter spirit, anything which follows refers to what Dr Frey happens to be voicing, and not to whatever may be his actual opinions.

Before coming to the specific question of human experiment, two general points arise. The first con-

\section{Key words}

Vivisection; anti-vivisection; animal experimentation; human experiment; human capacity; animal capacity; biological continuity. cerns the method of argument. It is an old one: that of reviewing a section of experience (in this case, experience of other people's opinion; reports, regrettably hearsay, about experimental work thalidomide, saccharin, and experience of the life of animals and of handicapped humans); and then of abstracting from this experience particular propositions which then become the subject of the discourse. A single instance (the tree in the quad, or the visual experience of a red patch) has sometimes sufficed to create such a proposition. This is a blameless, indeed common activity. The problem comes with 're-entry' to the experiential world. The proposition may be combined with others to yield further propositions. One such result here is: 'It is not possible to say, $a$ priori, that a human life of any quality, however low, is more valuable than an animal life of any quality, however high.' (Dr Frey does not put it so bluntly, but says only that nothing enables him to say this. I believe, however, that he is not merely wishing to report on his own psychological state, but wishes the proposition to be considered generally.) What use is this proposition? None that I can see. It explicitly assumes that there are scales of human and animal life, and explicitly compares the lower extreme of one with the upper extreme of the other; yet it gives no criterion as to where (or whether) the scales end. Even given these, and comparing (say) an anencephalic fetus with a favourite sheep-dog, over which people could make up their minds, all that has been done is to discuss extreme cases. What then? Few would accept that because a particular instance of animal life is more valuable than a particular instance of human life, therefore no human life is more valuable than animal life. The general proposition merely ends by regurgitating the sort of special case from which it originated.

This links with a second general point, the general philosophical mayhem created by continuity. The type of argument by which Dr Frey fails to find a 'dimension' by which humans differ from animals is one that can also be used to fail to distinguish between light and dark, sweet and sour, motion and immobility. Yet this does not prevent (for instance) the specification of a well-lit factory or an efficient dark-room, or the formulation of successful cooking recipes, or the measurement of velocity. The idea of continuity in the 'scale of 
creation' is an old and cogent one. It is true that individual species represent discrete steps, but within each species, variation is such as to blur the absolute demarcation in respect of any chosen character between neighbours. Dr Frey could have gone further, and added that no one has yet produced any logically rigorous principle of division at any point in the scale from the inanimate, through bacteria, protozoa, vegetables, insects and animals to man - whether reproduction, complexity, or evidence of responsiveness, purposiveness or sentience is considered. Even the leech will respond to morphine. But the recognition of continuity does not debar the drawing of operational divisions.

This brings us to the specific question of whether such operational distinctions can, or cannot, be drawn between humans and animals, particularly distinctions to which 'value' can be attached. Dr Frey's strongest candidate is 'self-enrichment', exemplified chiefly by a capacity for enjoyable experience. But he has to reject this as a discriminant between man and animal because he believes that a very, very severely mentally enfeebled person or a spina bifida child has less capacity for enrichment than a healthy animal. It is a comment on moral philosophy today that 'capacity for enrichment' should be advanced as the strongest index of value in human activity. In such a context, one cannot expect that other indices, such as capacity for goodness, altruism, responsibility, or forgiveness, would be admissible. But one need not resort to these. There is one respect in which the human has come increasingly to distance himself from the animal namely the capacity to accumulate his experience by the spoken and (especially) by the written and printed word. This means that successive generations build on their predecessors' achievements, not (as with a crystal, an anthill, or a coral reef) more and more of the same, but continually changing what they build. The scratches in the Lascaux caves lead to the Renaissance; Pythagorean harmonics in time grow up to the Bach fugue; Archimedes's method of exhaustion, transmuted in the 17th century to the calculus, becomes O-level mathematics for today's schoolboy. Man's mastery of the environment, initially little more than adequate for survival, is now so great as to arouse his deepest sense of responsibility and his deepest questions of meaning and purpose. Nor must this human capacity be linked only to the 'normal' human in perfect health. Human achievement owes much to the deformed, diseased, epileptic and insane; but perhaps only those familiar with the handicapped know that achievement is not restricted to geniuses, but can pervade all levels of personal and social relationships. (There is the medical point, too, that one must not assume a present handicap to be necessarily permanent: the cretin used to be a striking example of severe handicap, seemingly irreversible in 1890 , but curable by 1900 . Phenylketonuria provides a more recent example.)

If we accept that man can accumulate his experience (not only that of other men: he can and does accumulate his experience of animals) how does that affect the argument? It is not necessary to argue that an absolute distinction from the animal has been found. Indeed there is some evidence (though it remains inconclusive) for vestiges of a capacity to build a language and to frame abstract thought in the higher primates, although it is hard to see evidence of the use of these for progressive cumulation. But all that is needed is to recognise a quantitative distinction between man and animal sufficiently great to be accepted in practice as qualitative. That this is the case seems to me, whether or not the reasons are articulated, the general consensus. The capacity to accumulate, and thus to build on the past and to look to the future, is a quality, too, to which value can be attached, and a value which looks beyond personal enjoyment to the needs of other individuals. This constitutes an answer to the question 5) in my initial summary of Dr Frey's argument, and a rebuttal to 6) and 7), after which 8) and 9) lapse.

One might stop there, but Dr Frey's paper - from which an uninformed reader might suppose that no human experiment had hitherto taken place - calls for something more. One can now identify three approaches to such experiment: (a) The one argued above, which gives a greater value to the human than to the animal; this does not debar human experiment, but only introduces a coefficient to be applied to the choices to be made. (b) At the opposite extreme is an equation of human and animal value. This, too, fails to debar human experiment. The question becomes instead that of choosing animals or human beings for experiments, presumably simply by practical criteria such as scientific suitability (large animals such as man would need much larger apparatus), cost, and availability. The question of availability is interesting; it would entail consent on the part of a human subject. How does one obtain the consent of an animal? It is not possible for a human to speak for it, for that would deny the postulated human-animal equivalence. The question illustrates the crucial character of one's view of human and animal relationships. (c) In between, it seems, is Dr Frey's position, which appears to accept that there are different scales of value for human beings and animals, but argues that they overlap. Thus Beethoven is more valuable than a mouse, but the severely handicapped human is of less value than a healthy 'higher' animal. The implications of this are not worked out; but such a calculus would appear to legitimise the use especially of the diseased and mentally deficient. I doubt if this is what he intends.

More important, perhaps, is to make clear how much human experiment has been, and is being, done. I do not believe Dr Frey would have written as he has if he had adequately consulted the original medical literature, or medical scientists. Human experiment has a long and honourable, though still unwritten history. Some is severely ad hoc: experiments on effects of acceleration on the human body, leading to ejector seats; or on oxygen poisoning, high pressure, carbon 
dioxide poisoning, and the 'bends', to make diving safer. Some is to help to improve medical understanding: the cardiologist first passing a cardiac catheter on himself; self-curarisation; the paralysis of nerves by local anaesthesia, or nerve section, or vascular occlusion, to throw light on neurological problems. Much takes place in pharmacological work: early trials of metabolism, pilot studies on dose-level, analyses of mechanism of action. Unlike animal experiment no licence is needed, no annual return of the numbers of human experiments is needed, and no government office counts them. Thus it is not easy to estimate their number. But some indication is given by a single issue of just one monthly journal, the British Fournal of Clinical Pharmacology which contained 20 papers, covering 124 experiments on normal human subjects (both young and old) and 99 experiments on patients. Scale this up, and one may well doubt if there is scope for much more human experiment than is already conducted.

Dr Frey's argument raises yet other issues. One can well argue that if no distinction can be drawn between man and animals, then neither can it be drawn between the animal and the vegetable world. So one could ask, as one contemplates the insectivorous plant Drosera, responsive to sun, rain, and the nutrients of the soil, and exquisitely sensitive to chemicals, and watches it close a leaf around and digest an insect caught on its hairs, 'Can anyone say that this plant is less enriched by its experience than a lion as it devours a buck, or a man enjoying his dinner?'. But this merely emphasises again the importance of one's view of man's relation to the rest of creation. But these are not the issues at the heart of the debate about animal experiment. In practice, I take the most important to be the assessment of the scientific value of an experiment, of the knowledge or benefit to be gained, and of the suffering (if any) involved, and the question of how to balance these. It is ultimately a moral problem, and a question of responsibility borne both by the scientist and by the rest of society in the characteristically human task of removing ignorance and minimising suffering.

\section{Response}

\section{R G Frey}

\section{Department of Philosophy, University of Liverpool}

Professor Paton would have us believe that man's capacity to accumulate his experience by the spoken, written and printed word confers greater value on his life; but this generalisation does not help over the problem I posed.

A medical scientist engaged in serious work needs to perform experiments on retinas, experiments which in the end involve loss of sight and not in some accidental fashion; he may use the retinas of perfectly healthy rabbits or those of severely mentally-enfeebled humans. To put the matter somewhat elliptically, the scientist can blind the rabbits or blind the humans. How is this choice to be made? Presumably, Professor
Paton would point to the humans and maintain that they belong to a species that has the capacity to make significant advances on any number of fronts as a result of accumulated experience; but exactly how does this fact help with the case before us? These same mentallyenfeebled humans belong to a species capable of producing Beethovens, Mozarts and Schuberts, but that in no way makes them composers or confers on their lives any value. So exactly how is the fact that our species has been capable of great wonders supposed to help out in the cases of those humans far removed from any such wonders? Professor Paton writes: 'Few would accept that because a particular instance of animal life is more valuable than a particular instance of human life, therefore no human life is more valuable than animal life'. Of course not; nor did I suggest anything so silly. But the people to be used by the scientist are not fully normal humans but seriously defective ones, who are still such - they have eyeballs - as to be suitable experimental subjects. Clearly, Professor Paton has given us no reason for not carrying out the experiment upon the humans in question; for, to repeat, the mere fact that my species can produce a Beethoven does not per se make $m y$ life any more valuable than that of a mouse.

Professor Paton writes at one point about our having to obtain the consent of human subjects and of our having no means of obtaining consent from animals; but I should have thought he was unwise to make much of this. Animals may not be able to consent, but that does not appear to stop Professor Paton using them as experimental subjects; whereas, though it makes no sense to speak of obtaining the consent of the severely mentally-enfeebled, I presume he would recoil from their use as subjects for blinding. Why? What makes him hesitate in their case but go ahead in the case of rabbits? My strong suspicion is that he intuitively accepts human life as more valuable than animal life, even when all the grandiose talk of our capacities and accomplishments is inapplicable, and it would be interesting to know how he justifies this intuition.

Professor Paton speaks of my use of hearsay, my failure to consult medical reports, my making it appear as if no human experiments have been performed; well, here is his chance to nail down his accusations. I can point to a number of instances where rabbits with good eyesight have knowingly been blinded in the course of experimental work; I ask him if he can point to a single instance where a human subject, with otherwise good or perfect eyesight, has knowingly been blinded by a medical experimenter. If he can, then let him name names; if he cannot, then he might justly be accused of having failed to take my point, which, as readers will know, is that we do not do to defective humans all that we presently do in our laboratories to quite healthy animals. My interest is in why we do not. If the justification is that we think human life of greater value than animal life, then we must be prepared to face the facts, at least on the grounds I suggested, that (i) not all human life is of the same value and (ii) some human life has a value so low as to be exceeded by some animal life. 